\title{
Library Resources and
}

\section{Bibliographic Control}

\begin{abstract}
The future of academic libraries is discussed from the perspective of their resources and bibliographic control. Emphasis is focused on collection philosophy, book selection, the collection itself, resource sharing, adequacy of library space, preservation, new cataloging rules, a national bibliographic data base, and subject access. To provide a better forum for discussion of these matters and to assist in the solution of related problems, the author sees the need for a national library agency.
\end{abstract}

I HAVE LONG maintained the view that the human mind, or at least my own, is capable of dealing with only a limited number of problems at any given time. In other words, I can cope with a relatively small number of major concerns with any hope of success.

Now, I am not talking about the relatively unimportant matters that might concern me: the future of mankind, the possibility of nuclear war, pollution of the environment, alternate energy sources, and the like, nor the more personal issues such as whether or not I will ever be able to grow a decent lawn, or whether I should buy a snow blower, or whether it is possible to own a car that does not own you. I can handle all of these, mostly by not thinking too long about them.

My limitation on worrying is principally connected with my professional life. A few months ago I was asked by an old friend in the library education field to list the ten most important concerns that face me as an academic librarian today. After some cogitating, I began to compile the list. You will not be surprised, I am sure, to hear that the list contained the following, in no particular order of priority: financial support, cooperative activities, personnel issues and staff de-

Jay K. Lucker is director of libraries, Massachusetts Institute of Technology, Cambridge, Massachusetts. velopment, bibliographic control, automation and the new technology, space, educating library users, governance and management, access to new forms of information, preservation, and collection development.

Most of you will quickly recognize that my list of concerns contains eleven rather than ten elements. Actually, the only significance that has is that I stopped listing topics because I realized I had reached the limit of my worrying capacity, not because I had run out of ideas. A list of major concerns could well be twice the size of the above or, given the marvelous capacity of the human intellect to create problems even where they do not exist, even greater. Fortunately, my assignment for this conference was to discuss only a subset of the list I generated; but I shall try to do that in the perspective of the future of academic libraries in general.

The future of collections in academic libraries and the concomitant question of bibliographic access to these resources is by no means clear. What is apparent, to me at least, is that present trends cannot continue indefinitely. Present trends mean continued inflation in the cost of acquiring and processing materials; reduced financial support for libraries of all types; limitations on size, expandability, and flexibility of the buildings in which we house our collections; the physical deterioration of books, manuscripts, and other information sources; and the apparent 
lack of coordinated, cooperative planning to attack these problems.

I certainly do not mean to imply that nothing has been done; what I do believe is that much more needs to be done by individual libraries and librarians, by professional organizations, and by government at all levels. We are spending more and buying less; we are cataloging more and finding less; we are cooperating more but with limited results.

It would be presumptuous for me to suggest I have the complete answers for even some of these questions, but perhaps I can offer a few insights into how we might begin to attack them. Predicting the future is both hard and easy. It is hard for the obvious reason that there are many more unknowns than certainties. It is easy because we, or at least I, will probably not be around when the time comes that proves I was wrong. With these caveats behind me, let me try to anticipate what I think will be happening in academic libraries in the areas of resources and bibliographic control.

I recognize that this conference attempts to respond to the concerns of academic librarians from all types of institutions: public and private; research libraries, college libraries, community college libraries; small specialized collections and large general ones. I also realize that no set of principles, no formulas, no prescriptions for how to do it or how not to do it will work for everyone. The best I hope for now is that I can provide some ideas, some stimulation for further thought, some provocation-that is what I shall try to do at any rate.

\section{LIBRARY RESOURCES}

In the beginning there is book selection. $\mathrm{Or}$ is that the beginning? Flow charts of technical processes operations usually begin with selection and acquisition, but I believe collection development starts much earlier with the establishment of a collection philosophy. In my view, academic library collections of the future will be more specifically developed around a particular set of institutional needs.

Except for the largest research collections, buying for speculative or anticipated needs will inevitably be greatly reduced. This is a function both of financial necessity and accountability. Most of us do not have, nor will we ever again have, the resources to buy most or even a part of what our patrons might need. We will have to do a much better job of defining and obtaining what they will need.

\section{A Collection Philosophy}

Establishing an overall collection philosophy requires a number of steps. Certainly the first is to identify the institutional objectives that the library or learning resources center is supporting. What are the instructional, research, and extracurricular programs that require information resources? What are the levels of needs of each of them, and what are the institutional priorities?

In the past, most of us have not had to face the situation where programs are curtailed or canceled. Conversely, many have had to face the question of how to deal with new programs and new courses, new research interests, new centers, and, perhaps most commonly, new faculty, usually with the same total acquisition budget.

In the light of projections regarding student enrollment in the next decade and in the absence of a massive infusion of additional support for libraries, I am willing to predict that many more of us will be required to adjust library acquisition programs to a smaller set of institutional programs. It is essential, therefore, to identify in collection development terms not only the individual programs being supported, whether they be departments, schools, centers, or the like, but also the amount of resources assigned to each.

I would also suggest that the kind of gross allocation of funds, traditionally by academic department, that we have been using up to now will be inadequate for future planning. Think, if you will, of a number of not so hypothetical cases.

One, a college or university decides to discontinue a graduate program but to maintain an undergraduate major in that field.

Two, an institution decides to drop an undergraduate major but to maintain a small number of service courses.

Three, a school decides to suspend a program, but with the strong possibility that it 
may be revived in the future.

How do we as librarians respond? In order to be able to act effectively in response to changes in institutional directions, we must define our collection policies in terms of overall goals and objectives and also be able to identify resources accruing to specific programs.

Let me relate two specific cases.

About ten years ago, MIT decided to eliminate its program in mining engineering, a field in which it had been intensely involved for many years. Aware of this change, the libraries decelerated the acquisition program primarily as a result of fewer requests for new books and journals from the faculty and research staff and, of course, as a result of reduced needs for courserelated materials. Today, with a renewed national interest in alternate sources of energy, including coal, we are back in the mineral resources business. The problems are several: What shall we buy to support the new program? What did we miss in the past ten years that we will need for the present and future? And, most important, what will this all cost?

At Princeton, in the early 1970s, a decision was made to discontinue the graduate program in Slavic languages and literatures. The undergraduate program, however, was to continue, but on a reduced basis. How, we were asked, will the library respond? How much money can be saved? While we knew the total cost of materials in this field, it was extremely difficult to identify that portion accruing to the graduate program. The situation was compounded by the fact that graduate programs in Russian history, economics, and political science were continuing. Without going into details, I can report that in both these situations, decisions were made with less than the optimal amount of information.

I think we need better methods for accounting for library expenditures not only for the reasons given above but also in the event of more salutary changes. When new programs are established, when new centers are built, and when new faculty are hired, libraries should be able to respond rapidly and accurately with what perhaps might best be described as environmental impact statements.
If we are going to be more responsive to institutional needs, and I believe we have to be, librarians must be more systematic in allocating resources among competing needs. I recognize that this process in many instances may involve others including faculty and administrators, but I am sure you will agree that it is our responsibility to take a leadership position.

While intuition, tradition, persuasion, and collective action may have been and may continue to be ingredients in the allocation process, quantitative information is essential. We should certainly not become slaves to or victims of formula budgeting, but we do need hard data to support our recommendations and to enable us to compete for the institutional dollar.

Enrollments, size and composition of faculty, research interests and programs, and information on publishing trends and costs should all be part of the allocation process. Data on collection use should be assembled and fed back into the allocation process. We should view this process as a positive and productive means for ensuring equitable utilization of resources, not as a defense against discontent.

\section{Book Selection}

Book selection is an imperfect science at best, if it is a science at all. I firmly believe that book selection belongs in the first instance in the hands of those who should know the most about it-the professional librarians. I also believe it cannot be done in a vacuum. Only with maximum information on institutional needs, on faculty and student interests, and on the use of existing collections can we select new books and serials for our libraries.

Developing knowledge about what we need requires that librarians become intimately involved in the educational process. Serving on faculty and administration committees, answering reference questions, providing formal and informal instructionin total becoming an integral, dynamic, functioning member of the academic community is the best way of becoming an effective selector. Academic libraries need to have more staff involved in the selection process, and we need to develop a high level of subject competence among as many 
of them as possible. Faculty and student input is necessary and it is good, but as we all know it is uneven, often provincial, and frequently unreliable.

The importance of evaluative mechanisms in book selection cannot be overlooked. As we continue to be faced with the necessity for making harder and more complicated decisions about what to buy and what not to buy, we need all the help we can get. The availability of critical and authoritative reviews not only for books and serials but also for large microform sets, films, videotapes, records, cassettes, maps, and other publications is not only desirable; it is essential. And we, as librarians, must be an integral part of the process.

Sharing resources, in my view, means not only physical resources but intellectual ones as well. Let me go one step further. I think librarians ought to take a more aggressive role in identifying what needs to be published as well as reacting after the fact to what has been published. I would urge a stronger partnership between the library profession and the publishing community for the benefit of both.

\section{Library Collections}

What of library collections themselves? What will they look like in the next decade and beyond? For the immediate future, I do not foresee any revolutionary changes in academic library collections. I do see a continuation of a number of trends that have occurred during the recent past. We will continue to buy books, and they will be the principal means by which we collect information. Except for large research libraries, we will be buying mostly new books and few older ones.

Libraries having to acquire retrospective materials will be relying much more on microforms than in the past not only because of cost but also because of space limitations. I assume in connection with microforms that the quality and diversity of reading and reproducing equipment will improve, and the unit price of such equipment will decrease. Original publication in microform will continue to expand. The dominance of this medium that has occurred with theses and technical reports and is now extending to U.S. government documents will in all probability have a substantial impact on publishing of state and local [government] documents, legal materials, and, perhaps of greatest potential, serials.

\section{Resource Sharing}

If anything produces a crack in my already clouded crystal ball it is when I start thinking about the potential impact of resource sharing on collection development. Nothing I know of holds such great potential for academic libraries; yet nothing is so full of complications and pitfalls.

Let me start out by saying what I think resource sharing is not. It is not a substitute for collection development in individual libraries. Each of us has the responsibility to do everything possible to provide as much information in our own libraries as is feasible for the present and anticipated needs of our primary constituency.

It is clear, of course, that we cannot provide everything that our users need or may need, and it has become apparent, in the light of present financial trends, inflation, and the steady increase in the total amount of information published, that the percentage of that elusive "everything" is steadily decreasing. Defining what is a reasonable level of local fulfillment of needs is both necessary and difficult. Most faculty members would, I am sure, be quite willing for their institution's library to establish a goal of less than 100 percent as long as it is for someone else's discipline.

Leaving the obvious aside for the moment, however, I would suggest that this can be done in an approximate if not absolute manner. As part of the Collection Analysis Project undertaken at MIT last year and continuing through the present, we are attempting to establish levels of collection comprehensiveness for more than seventy-five subject areas.

While we will start with the general categories familiar to all of youcomprehensive, research, etc. -I expect we shall be able in the end to be considerably more precise. The ability to define these levels in a qualitative as well as quantitative manner will be extremely valuable as we enter into bilateral and multilateral resource-sharing arrangements.

The second thing resource sharing is 
not-and I am really speaking here to our administrators-is a means of cutting library budgets. It should, however, enable us to be more effective with the funds we have. The ideal resource-sharing arrangement would permit a library to cancel subscriptions to least often used journals and not to order certain monographs, releasing those funds for more substantial development of fields where there is strong local interest.

Resource sharing is not a one-way street. There must be identifiable and visible benefits to all participants. Libraries should cooperate in areas and at levels where there is the potentiality of reciprocity. This argues for sharing within disciplines rather than among disciplines. Each library engaged in a resource-sharing arrangement should undertake to supply the basic needs of its own user community.

The sharing takes place when the cooperators can agree to apportion acquisitions above that basic level with each taking responsibility for a portion of the subject field. This guarantees borrowing in both directions and avoids imbalance. It also promotes understanding among all users and avoids a situation where faculty and students in a subject field see only a one-way flow.

Finally, resource sharing is not a panacea for all that ails our collections. We still have to battle for more resources and we still have to be able to justify our acquisitions decisions. Resource sharing is an adjunct to collection development, essential for the long-term survival of academic libraries, but even in its most ideal form, one of several means for improving service to users.

Resource sharing begins at home, or at least it should on multilibrary campuses. While it is perhaps erroneous to speak of intralibrary loans and intralibrary cooperation, this is no small problem in many academic institutions. I have often thought that if there were some horrible catastrophe and only two scholars were left in the world, each would want a departmental library.

Let me assure you: I do not propose to sermonize about the pros and cons of departmental libraries. As a matter of fact, I support the concept both theoretically and pragmatically. I do believe, however, that we must find ways to ensure that our dispersed collections are based on sound philosophies of collection development and that we implement this through coordinated collection development. This is no mean feat, given the growth and complexity of interdisciplinary studies and the fuzzing of traditional departmental scholarly lines.

How, then, can resource sharing be used as a positive force in collection building? In the case of research libraries, there are many examples of bilateral and multilateral cooperation. I would include as examples the Center for Research Libraries, the Research Libraries Group, the National Program for Cataloging and Acquisitions, and the Farmington Plan, as well as a number of compacts involving two or three institutions.

In looking ahead, I anticipate that the number and diversity of such programs can only increase and that they will involve more libraries and many libraries not presently involved in these ventures. The prospect of a national periodicals center or national periodicals system could have a tremendous impact on every academic library in this country; and I will have more to say about this program shortly.

First, however, let me move away from research libraries and national programs and talk about the link between collections and cooperation in the arenas of smaller academic libraries-those of two- and fouryear undergraduate institutions. None of us needs to be reminded of the great progress that has been made in resource sharing through the advent of cooperative cataloging networks like OCLC, WLN, BALLOTS, and others with which we are familiar.

The availability of holdings information in these data bases has had a remarkable effect on load leveling of interlibrary lending. As the administrator of a library that fits into the category of "net lender," I applaud and welcome this shift. I am delighted to know that the flow of materials among smaller academic and public libraries has increased dramatically, and I am equally pleased that the larger research libraries are able, as never before, to call upon some of these same institutions.

I would argue, however, that the impact of cataloging networks on collection development has been minimal. The reason 
for this is, in my view, that we have been only passive users of the capability available to us. Given the challenge of diminishing local resources, we shall have to be more aggressive, or surely we will not succeed. I have no illusions, however, of the inherent difficulty in such a philosophy.

Cooperation in collection development is extremely problematical in the absence of institutional compacts. In order for two libraries, any two libraries, to undertake a program that calls for the delegation of acquisition responsibility, there ought to be some agreement between the schools they serve. I think we will not see a major shift in collection development practice until there is a change in the way that colleges and universities establish and disestablish teaching and research programs.

Pessimistic as this must seem to all of you, experience has indicated to me at least that this is the case. Let me provide an example.

The libraries of Brown University and Massachusetts Institute of Technology are engaged today in trying to develop guidelines for cooperative acquisitions in one or more subject areas. We know already that we will have to find such areas among the disciplines in which both institutions are deeply involved. Let us suppose that we find some subjects or parts of subjects that qualify. Let us suppose further that we can actually identify a body of information that because of various factorslanguage, cost, and, principally, patterns of past use-would qualify as being needed in only one of the two libraries. Let us assume further that we can agree as to which library will buy what serials and monographs.

The key question still remains: Can we proceed without some sort of cooperative agreement between the two parent institutions? I wish I could tell you that I have an answer to this question. I do not. All I can say right now is that we are going to do the best we can with what we have and what we know. I can also say that I am doing everything I can within my own university to link cooperative programs to library collection development.

The above notwithstanding, I do think a great deal has been accomplished with regard to cooperative collection development. Many libraries are involved in networks where union lists of serials are used not only for interlibrary loan but also for acquisition decisions. Groups of libraries have gotten together to share the acquisition of large sets or expensive materials. Libraries are beginning to think about cooperative retention of serials and older monographic material. We are also talking about working jointly in connection with preservation.

My personal view is that in the long run these programs may have a greater impact on library budgets and may be a more practical way of shared collection development than attempting to develop agreements on acquisition policy where colleges and universities continue to try to teach everything to everyone.

\section{A National Periodicals Center}

If you have not already read the report of the Council on Library Resources (CLR) on a national periodicals center, I commend it to you. Assuming you have read it, I will not attempt to summarize its contents; but I would like to reflect a moment on why I think this program is important and, yes, essential, for college and university libraries. Periodical subscriptions continue to take a bigger and bigger bite out of our acquisition budgets. We have to add substantial sums of money merely to keep up with current subscriptions while the number of new titles appearing each year continues to haunt us. Where will it all end? Not, I hope, with the collapse of libraries as we know them, and not, I am sure, with the demise of the publishing industry.

A national periodicals center is a viable answer to this problem. It would, if established, provide, in the words of the CLR report, "an efficient, reliable, and responsive document delivery system for periodical literature." More important for us, such a center would enable individual libraries to make more effective decisions on binding and preservation of existing collections and on the acquisition of titles not currently held.

The center would also promote local and regional resource-sharing arrangements for the periodical literature. Individual library decisions on the acquisition of titles would still be made on the basis of local needs, but the impact on binding and microfilming 
budgets of such an operation could be substantial.

Beyond its immediate impact on individual library development, a national periodicals center as envisioned in the CLR report could have some additional effects on the future of academic library collections.

First of all, the center could have an influence on the actual publication of periodical articles. Two possibilities are provided in the report: one would be the publishing of abstracts or synopses with an article distribution service; the second, the possibility of on-demand publishing. Implicit in this type of operation and in the rest of the recommendations made in the report is that publishers' rights and interests will have to be protected not only in terms of copyright but also with regard to economics. Think, if you will, however, of what on-demand publishing might mean in terms of space requirements and binding budgets. Think also of how much more information could be acquired under such a system.

The second exciting possibility that the national periodicals center offers is that it might be a prototype of similar centers for other types of material. Collections of monographs, state and federal documents, microforms, and technical reports appear to be possible candidates. This is not a paid or even unpaid endorsement of the CLR report on my part. I do think, however, that it behooves us as responsible members of the library community to read it, to discuss it, and to respond.

\section{Interlibrary Loan}

Before leaving the subject of resource sharing and the future of collection development, I would like to speak briefly about a matter of more immediate concern. As most of you know, the National Interlibrary Loan Code, last revised in 1968, is being reviewed by a committee of the American Library Association. A great deal has happened in the library world since 1968 that justifies a major expenditure of effort in proposing changes in the code: the rise and growth of library networks, the use of telecommunications and computer technology in the lending process, and a new copyright law, to mention only the most significant.

In addition, a number of other questions arise in any discussion of interlibrary loan. To what extent should interlibrary lending at the national level take into account the needs of undergraduates as well as the needs of the researcher who is not connected with a university? How can we strike a balance between resource sharing and the need to serve our primary constituency? How can the code promote the development and use of interlibrary lending at the level of local and regional consortia? Is the scope of materials as defined under the code too narrow? Or is it too broad? Is the concept of "in-print materials of moderate cost" obsolete? What about the lending of genealogical materials?

The new code should, of course, reflect the requirements of the new copyright law and should, in addition, cover a wider range of materials than before such as films, videotapes, and audio transcriptions. As a member of the committee responsible for drafting a revised code I can tell you that all these questions and many more concern me, and we will try to develop responses to as many of them as possible.

Some of you who are involved in interlibrary loan have already been contacted for suggestions and comments about the code. I want to use this opportunity to extend an invitation to any of you who have not been contacted to date and who have ideas as to how a revised interlibrary loan code might improve the sharing of resources, to write to me at the MIT Libraries. I will not promise that we will adopt all of your suggestions, for I have seen already that there is a wide range of views, even among ARL interlibrary loan librarians, on some of the issues described above, but I will see that they are all considered by the committee.

\section{SPACE AND LibRARY RESOURCES}

In looking back at my original list of concerns, I see two other topics that I would like to relate to the matter at hand-the future of library resources. The first is space. No one would deny that space is a resource, and I can tell you from recent experience that it may be a more valuable resource than money, particularly on an urban campus.

If some of the library directors in the audience are not worrying about their buildings, it is either because they are among 
that ever-diminishing group who have managed to convince their administrations that a new building or a major renovation or expansion has a higher priority than other pressing needs or because they have given up all hope.

It seems to me that it has been and will continue to be increasingly difficult to justify and support indefinite expansion of academic library buildings. This is not to say that many of our facilities are not outmoded, overcrowded, and inefficient. It is also not to say that, in some cases, new buildings or renovations are not necessary. I am concerned, however, that the supply of capital funds for library buildings is limited.

Despite all the inhibiting factors that we have noted for years, library collections continue to grow. They are growing, in many cases, at a slower rate than in the glorious sixties, but growing nonetheless. I do not know if I have a universal solution for this problem, but let me for a few minutes share some personal views about what might be the way to approach the next few decades.

\section{Collection Size versus Collection Use}

Painful as it may be, we must recognize that not everything in our collections is used to the same extent. Some books are used heavily when first acquired and seldom thereafter. Some books are not even used when first acquired, but I think we are doing a better job in book selection and are becoming less vulnerable to criticism in this area.

Now, I am not talking here about the very large research collections that build for the future as well as for the present, but even such libraries are becoming more cognizant of the need to relate current acquisitions programs to current teaching and research. For the majority of libraries represented at this conference, however, the problem of collection size versus collection use is a real one. It does seem to me that there are positive prospects on the horizon to help us face this situation.

A national periodicals center could have significent impact on the size of academic collections by enabling libraries to discard or transfer files of seldom-used back files of journals.

As a corollary, I envision the growth in number and importance of regional depos- itories of serial collections. While it is only in the thinking stage at present, I can tell you there is some possibility that such a facility will be established for the Boston Library Consortium. This prospect, however, is not without its difficulties. Among the obstacles to such an arrangement are questions of ownership, institutional prestige, access and delivery, and relation to other regional and national programs.

\section{On-Campus Storage}

Another approach we are taking at MIT is the establishment of an on-campus resource-sharing center. While similar in many ways to storage facilities already in existence at other universities, our approach to this concept does have some unique features. To begin with, we are going to develop our facility in two stages.

The first, with support from the BoothFerris Foundation, will be to set up a model facility in a smaller building where we will endeavor to develop policies and procedures and to set up operations in a laboratory mode, thus enabling us to make changes without causing perturbations in a large system. The MIT Resource Sharing Center will be on the campus, fully accessible to users but with the emphasis on quick delivery. We envision a facility that will handle the increase in our collections for fifteen to twenty years with the view that during that time the effects of such things as the national periodicals center, new forms of publication, and technological advances might provide an even longer-range capacity to handle the growth of the libraries. The possibility of local and regional cooperation in storage of older materials is another factor that could increase the time before this building becomes full.

\section{Space and Resource Sharing}

If space is at such a premium, why haven't we done more to cooperate in the sharing of older resources? The answers are complex, and it is perhaps unnecessary to dwell on the past. I do believe we must begin thinking more imaginatively about this matter, and, to me, the "we" means all of us.

One avenue that appeals to me is to discard any preconceived notions about cooperating only among libraries of the 
same type. I wonder if we would not serve ourselves and our users more effectively if we started thinking about sharing space among libraries of many types-public, school, academic, and special. Is there not some value in a partnership of all kinds of libraries, joined together with the common goal of sharing?

Would not special libraries be willing to support a local or regional storage facility that would provide back files of serials and older monographs? Are there not city councils or library boards who could be persuaded of the economics of supporting a regional resource sharing center that would have the effect of inhibiting the physical growth of local public libraries? Surely state libraries and library agencies have a major stake in seeing that public funds are used for collection development and improved library service rather than for the housing of copies of little-used and redundant material.

The coordination of local and regional centers with national resources like the national periodicals system could conceivably provide a solution to the long-range space needs of academic and nonacademic libraries.

\section{Preservation}

A second topic I should like to mention briefly is that of preservation. We are faced today with the specter of accelerating deterioration of our collections, many of them representing unique materials.

It is obvious that there is not enough money available for all libraries to preserve even a major portion of their collections. If we are to preserve the record of the past, we are going to have to do this collectively. I feel strongly that the time for a national program of preservation of library materials is now.

This program should include the identification of those collections or portions of collections that represent a national resource. The program should be coordinated with national centers like the Library of Congress and the national periodicals center. Training programs for library staffs and research in the scientific and technical aspects of preservation should be supported and funded.

I would be remiss at this point if I did not recognize the tremendous support that libraries and archives have received in recent years from the National Endowment for the Humanities and the National Historical Publications and Records Commission. Much more remains to be done, and we academic librarians must take a major role in this area.

\section{BIBLIOGRAPHIC CONTROL}

We are entering a period of great change and considerable uncertainty in terms of the future of bibliographic control in academic libraries.

\section{AACR 2}

There is certainly no one at this conference who is unaware of the significance of the date January 1,1981 . It is almost as certain that most of us are relieved that that date has recently been changed from January 1,1980 .

In either case, however, the impact of the decision of the Library of Congress to close its catalogs and to adopt the second edition of the Anglo-American Cataloguing Rules (AACR 2) will be far-reaching, expensive, and complicated. The very fact that the date of this conversion was delayed after a meeting of representatives of major library organizations with the Library of Congress is in itself significant and worthy of comment. I do not propose to dwell here on the arguments for or against delaying the implementation of AACR 2. The decision has been made and I, for one, welcome the additional time available to develop plans to cope with the change.

What is important to me is that the manner in which the library profession approached the question indicates the need for a higher level of coordination of bibliographic control on a national basis. There is at present no organization, no agency, indeed no mechanism for the consideration of questions like AACR 2 that brings together all the concerned parties.

For this reason alone, but also for the reasons I have stated earlier, the prospect of a national library agency as envisioned in the CLR report on a periodicals system holds a great deal of attraction for me. Had we had such an organism in place last summer, I believe the difficulties encountered in considering the time frame for AACR 2 and concomitant problems would have been avoided or at least lessened. 
A national library agency could also provide an umbrella for research, planning, and development of such activities as a national bibliographic data base, national programs for cooperative collection development, a national preservation program, resource sharing, and regionalization.

Leaving the events of the past few months behind us, we must still face the inevitable. AACR 2 will be upon us in a little more than two years. Libraries will have to decide, and soon, whether they will close their card catalogs and start new ones, whether they will try to integrate cataloging produced under the new rules with that produced under AACR 1, or whether they will establish new bibliographic apparatuses like on-line catalogs, COM catalogs, or some combination thereof.

I am not an authority or even a knowledgeable amateur in this complex and intriguing field. Unraveling the intricacies of cataloging rules requires experience and knowledge that only years of working with them provides.

On the other hand, there are going to be shock waves resulting from these momentous changes that will have impact on other facets of library operations beyond technical services. From personal experience I cannot emphasize too strongly the necessity for close cooperation within academic libraries to meet the challenge.

It is important for library directors to become as much aware as possible of the financial and political implications of the impending changes. Reference and information service specialists must be intimately involved in the planning and implementation of these changes not only because they will have to interpret them for the library's public and teach patrons how to work with a whole new set of access principles, but, more important, because these staff members know, as well as anyone can know, how users approach and interact with the bibliographic tools available.

\section{A National Bibliographic Data Base}

Beyond the immediate prospect-or some might say, specter-of AACR 2, however, lies another goal: the potentiality of a national bibliographic data base.

The principle embodied here is not very complex; the planning and implementation certainly are. What is being proposed by the Association of Research Libraries in close cooperation and consultation with the Library of Congress is a system of decentralized input to a national bibliographic data base under a set of carefully conceived and well-developed rules with the objective of sharing responsibility for providing original cataloging information and offering access throughout the country to a wider range of library materials.

In some ways this program might be visualized as a Farmington Plan for cataloging. Individual research libraries would accept responsibility for inputting records in subject areas or languages for titles not already in the MARC data base. They would necessarily have to agree to a set of cataloging standards that cover not only individual descriptive elements but also the general framework of the data base.

At present, the plan calls for a group of six sets of standards that would be applied to all records entered by cooperating libraries. For overall descriptive cataloging, AACR 1 would apply to original cataloging prior to 1981 and AACR 2 to that after 1981.

While a single classification system is not prescribed, numbers would have to follow standards set by the Library of Congress for the LC and DDC classifications, by the National Library of Medicine, or by the National Library of Agriculture. Subject headings input at the national level would likewise have to be consistent with Library of Congress subject headings, the Medical Subject Headings (MESH), or the NAL subject headings.

The appropriate fields in the machinereadable record format would have to follow the national standards, but libraries could also include subject headings from other systems such as Sears as long as the records were tagged accordingly. Name headings following the LC form or a national authority system assuming such were developed are the fourth standard. Anticipating an authority system for series headings, this would be the fifth element. The final mechanism for ensuring consistency is the MARC format for machine-readable records.

It is obvious that the concept of a national bibliographic data base not only is extremely complicated but also requires a 
tremendous amount of coordination and planning. We should all be heartened to know that the Council on Library Resources has received financial commitments from various sources to work on establishing the machinery and begin putting together all the elements required for a national bibliographic system.

It is not difficult to find positive implications in this program for all our libraries. First, the availability of cataloging information for more books and other materials must, in time, lower the cost of cataloging for individual libraries. Second, the existence of bibliographic information in the several cataloging systems already in existence has proved to be a strong positive force in the sharing of resources; increasing the amount and diversity of this information can only improve the situation.

\section{Subject Access}

I would like, at this point, to move from one aspect of bibliographic control that is strongly oriented toward the descriptive to another that emphasizes the intellectual content of the material being indexed, namely, subject access. We are in the midst of exciting changes that affect the ways in which we and our users approach information from the context of its subject content. The growth in number and extension in coverage of on-line data bases is something of which we are all aware. The ability to search extensive files of information using multiple access points and combinations of subject descriptors has revolutionized the literature searching process.

We have developed a whole new field of library service and in the process have become more aware not only of the power that the computer provides in literature searching but also of the inadequacy of some of our more conventional approaches to subject access by comparison.

Let me, for a moment, share with you some of the issues facing librarians and others in connection with subject access and some ideas about how they might be attacked. The substance of what I have to say comes from a recent meeting on subject access sponsored by the Committee for the Coordination of National Bibliographic Control held in Springfield, Virginia, in October 1978.
This committee is supported by the National Science Foundation, the National Commission on Libraries and Information Science, and the Council on Library Resources. Participating in this workshop were representatives from libraries-academic, public, and special; abstracting and indexing services; information dissemination centers like BRS, Lockheed, and the University of Georgia; publishers; and users of subject access systems.

To begin with, I should define subject access. Prior to the workshop the planning committee of which I was part asked each participant to provide a definition of the term. As you might expect, the responses were diverse and interesting. In the interest of time, however, let me use the definition that the planning committee put together: by subject access is meant the use of words, phrases, or symbols to represent the intellectual content of recorded knowledge for purposes of organization and research.

In assessing the current state of subject access, we attempted to describe the present situation within a framework of four groups that are either involved in the production of subject systems or are distributors or users of them. These were the Library of Congress, abstracting and indexing services, information dissemination centers, and publishers. One of the major concerns of the planning group that set up the workshop was the matter of subject control of monographic literature.

The problem can be put into perspective when one compares the multiple subject access points available in a system such as Chemical Abstracts or MEDLINE with those available in the conventional subject catalog found in most libraries, whether through a card catalog or a computerproduced display of a card catalog. A nonfiction monograph cataloged by the Library of Congress may carry two or three or occasionally four subject headings; the average for monographs cataloged by Chemical Abstracts is between 5.5 and 7.5 and the average there for papers is 9 , with some having as many as 25 subject descriptors.

The problem, however, is not only with numbers. The Library of Congress subject heading system, with which we are all familiar, has a number of strengths: it is relatively universal, at least among academic li- 
braries in North America; it is large-almost one-third of the 21 million cards in the LC main catalog are subjects; it is authoritative; it is documented.

This list also has a number of weaknesses: there is no underlying code or theoretical basis as, for example, with the AngloAmerican Cataloguing Rules for descriptive cataloging; it is difficult to change because of the tremendous amount of work involved in correcting existing records; it is inconsistent in the formulation of headings, in the use of phrases or subdivisions, and in punctuation. Some say the list is biased. Some say it is changing too much; others, too little. If these problems were not enough, just consider the effects on subject catalogs of the LC decision to close.

The question of subject access to monographic literature and the related matter of LC subject headings are only a small portion of what has been identified as the "subject access problem." There are several other issues that developed during the workshop. It is interesting to note that while most of the participants and most of the discussion concentrated on on-line data bases, there are in most instances correlations and implications for subject access through library catalogs.

A major concern was the diversity of subject access vocabularies. There is almost no carry-over from one data base to another. Subject terms used in one discipline may not be used in another, or if they are, they may have an entirely different meaning. An example used was the term "bridge." Think of the many ways this descriptor might be used in dentistry, civil engineering, electrical engineering, philosophy, semantics, music, and so on.

Another group of questions involves the user of subject access systems. For a given tool, whether it be a printed index, on-line data base, or subject catalog, there are a variety of users in terms of education, interest, and approach, and each user may be querying the system for a different purpose. It is clear that we do not know enough about how people use subject indexes, and, beyond that, we know even less about how questions are formulated.

A third general area of concern is economics. How can we measure the cost effectiveness of a subject system? Can a system ever be too large? How do we remove or purge seldom-used citations or subject entries from a system, and should we? Is there some way to provide a qualitative indicator for indexed information, and is there some relationship of this question to that of user feedback? How can users of a system influence its future direction, and is there any value in having a dynamic system that contains the results of previous searches accessible to later users?

Other issues are equally important but do not fit neatly into the categories listed above. Can we improve direct user interface with on-line retrieval systems? How do we improve bibliographic coverage, particularly of the periodical literature, in the humanities? How, indeed, do humanists use the subject approach? If it is different from the way in which scientists and social scientists and engineers do it, what are the differences, and how can they be reflected in the design of subject indexing systems?

Finally, there is an issue that many librarians have puzzled over for a long time: how can we relate library subject catalogs to online retrieval systems both for searching purposes and for item identification?

It would be exciting if I could tell you at this point that we solved all or even a few of these problems. We did not. We have, however, made a good first step by bringing together a group of specialists with diverse backgrounds to identify the issues involved in subject access and to suggest ways in which they might be attacked. The specific suggestions that will come from the Workshop on Subject Access are still being written. These ideas, along with a summary of the proceedings, will be available in the near future.

In advance of that, however, let me list some of the possible directions that future research and development might take:

1. Improving multifile subject access through building composite indexing records from several sources.

2. Increasing cooperation between the abstracting and indexing services and national libraries to work toward more consistent subject vocabularies in areas of mutual interest.

3. Increased support for the development of subject access systems in the humanities.

4. Research on the effectiveness of vari- 
ous subject access schemes including card catalogs, vertical files, on-line data bases, printed abstracts and indexes, and back-ofthe-book indexes.

5. Research on the process of asking questions.

6. Improved subject access for specialized types of material: maps, audiovisual, manuscripts, materials for the handicapped.

\section{Scope of the Catalog}

In thinking about the future of bibliographic control, I am concerned that we may have been tied too much to the concept of catalogs' being designed primarily to reflect an individual library's holdings. One thing I hope for in the catalog of the future, regardless of what form that mechanism takes, is that its scope will extend as far as possible beyond what is in a particular library.

Let me provide a local example. If Brown University and MIT cooperate in the future in collection development and if one library agrees to forego materials because the other library acquires them, why shouldn't a record of the book or serial or other material appear in both catalogs? In my opinion, library catalogs should, insofar as possible, reflect the totality of what is available to a user, not just what is on the shelves or supposed to be on the shelves.

\section{Conclusion}

I would like to conclude by offering a few generalizations on the future of resource development and bibliographic control with the full knowledge that I might, at some point in the future, be confronted with a set of unrealized predictions.

1. Academic library collections will be more diverse in terms of format but more specific in terms of relevance to teaching and research programs.

2. Collection development will take place in an atmosphere of limited funds, limited space, and a steadily increasing publishing output.

3. Cooperation in collection development will grow but will not supplant or even substitute for a significant portion of individual library collection building.

4. National centers containing information needed by library users and having the po- tential for providing this information quickly and economically will play an increasingly important role in local library decisions on acquisitions and on retention of older materials.

5. New forms of publication, such as publishing on demand, and new means of supplying information, like videodiscs, will affect collection development in academic libraries but will not solve the overall problem of physical growth.

6. Library card catalogs as we know them today will slowly go out of existence and be replaced, first by physical substitutes created through computerized cataloging, and later by on-line catalogs.

7. Academic libraries, including those of many colleges and universities as well as the large research libraries, will play an increasingly important role in the creation of a national bibliographic data base.

8. AACR 2 is not the end. It is not even the beginning of the end. There will be an AACR 3, and probably an AACR 4. One would expect, however, that prior to that inevitability there will be a national library agency to coordinate library services and programs for the benefit of users and librarians alike.

I have been involved with academic and research libraries for almost twenty-five years. During that time I have never given serious thought to doing anything else. Like many of you, I have sometimes been depressed by a seeming lack of progress. Like many of you, I have often been encouraged by the tremendous advances that have taken place in academic libraries both in terms of physical resources and human resources. I am optimistic by nature, and I am completely optimistic about the future of academic libraries.

Today is a great time to be a librarian; the challenges we face will stimulate our imagination and test our flexibility, but the prospects are unlimited. The first national meeting of the Association of College and Research Libraries is significant for many reasons, but it is most significant for me in that it comes at a time when all of us are facing some of the most difficult and complex problems librarians have ever encountered. I believe we will solve these problems and others to come because we have done it before. 